\title{
Corporate Investment and Portfolio Returns in Japan: A Markov Switching Approach
}

\author{
Chikashi Tsuji ${ }^{1}$ \\ ${ }^{1}$ Faculty of Economics, Chuo University, Tokyo, Japan \\ Correspondence: Chikashi Tsuji, Professor, Faculty of Economics, Chuo University, 742-1 Higashinakano, \\ Hachioji-shi, Tokyo 192-0393, Japan. E-mail: mail_sec_low@minos.ocn.ne.jp
}

Received: February 1, 2018

Accepted: February 21, 2018

Online Published: March 8, 2018

doi:10.5430/jms.v9n2p1

URL: https://doi.org/10.5430/jms.v9n2p1

\begin{abstract}
This paper explores the profitability of four Japanese higher return equity portfolios and their linkages between corporate investment factor return, the so-called conservative-minus-aggressive (CMA), suggested by Fama and French (2015). Our empirical examinations derive the following evidence. First, in the four Japanese equity portfolios, the smallest and the highest operating profitability portfolio presents the highest return. Second, the smallest and the highest book-to-market (B/M) portfolio, the smallest and moderate investment portfolio, and the smallest and the second strongest momentum portfolio also record higher excess returns than the overall equity market in Japan. Moreover, our analyses via two-regime Markov switching models evidence that for all the four Japanese equity portfolios, there are clearly two regimes: one is positively related to CMA and the other is little or negatively related to CMA. Furthermore, our analyses also reveal that recently, all the four Japanese equity portfolios yield higher returns than CMA with showing weaker linkages between CMA.
\end{abstract}

Keywords: asset pricing, Japanese equity portfolio, Markov switching model

\section{Introduction}

After almost 10 years from the three-factor asset pricing model of Fama and French (1993), Fama and French (2015) extended their three-factor model to a five-factor model. In the five-factor model, they added a corporate investment factor and an operating profitability factor to their three-factor model. Although the positive relation between operating profitability and stock return is intuitive, how are the corporate investment factor return and equity portfolio returns related? Are there any regime shifts in the relations?

To clarify these matters, this study investigates Japanese equity portfolios sorted by several fundamental factors such as firm size, ratios of book-to-market (B/M), operating profitability, corporate investment, and momentum by using Markov regime-switching models (e.g., Hamilton, 1989; Filardo, 1994). We point out that in asset pricing literature, many empirical examinations for factor returns and asset portfolios were conducted for the US; however, not enough research for Japanese equity portfolios has been performed. Hence, our analyses of the performances of Japanese equity portfolios and the relations of Japanese equity portfolios and Fama and French's (2015) corporate investment factor return (conservative-minus-aggressive (CMA)) by employing two-regime Markov switching models are valuable. The derived findings from our empirical analyses in this paper are as follows.

First, in our four Japanese higher return equity portfolios, namely, the smallest and the highest operating profitability portfolio presents the highest return. While excess overall equity market return in Japan is 0.11 percent per month, the smallest and the highest operating profitability portfolio exhibits the average excess return of 0.66 percent per month in Japan. Second, the smallest and the highest B/M portfolio, the smallest and moderate investment portfolio, and the smallest and the second strongest momentum portfolio also record higher excess returns than the overall equity market in Japan. These mean the effectiveness of building bivariate-sorted equity portfolios in Japan.

Moreover, our analyses via two-regime Markov switching models evidence that for all the four Japanese equity portfolios, there are clearly two regimes: one is positively related to the investment factor return and the other is little or negatively related to the investment factor return. In addition, our analyses reveal that recently, all the four Japanese portfolios yield higher returns than the investment factor return with showing weaker linkages between the investment factor return. These new findings derived from this study are the contributions of this paper. 
As for the rest of this paper, in Section 2, recent related research is reviewed; in Section 3, the data used for our study are explained; and in Section 4, the model for our empirical analyses is introduced. After these, Section 5 documents our empirical results and Section 6 concludes the paper.

\section{Recent Literature Review}

In this section, recent literature applying regime switching approach is briefly reviewed. Recently, using Markov switching approach, Chun et al. (2014) investigated US corporate bonds' credit spread determinants by incorporating regime switching between different economic, credit, and monetary states. They suggested that in their regime-shifting framework, market, default, and liquidity factors had superior explanatory power since those factors were related to regimes. Filipova et al. (2014) developed a multivariate dynamic term structure model by considering a threshold regime switching model. This study also suggested the framework, in which the regimes were governed by thresholds and were directly linked to economic fundamentals.

Using the US data, Baele et al. (2015) estimated a New-Keynesian macro-model by incorporating regime-switching behavior in macro-shocks and monetary policy. They found that output shocks shifted to the low volatility regime around 1985 and inflation shocks shifted to the low volatility regime around 1990. Focusing on the convenience yield and employing a regime switching framework, Almansour (2016) modeled the crude oil and natural gas futures term structures. Specifically, this study extended the model of Gibson and Schwartz (1990) to allow for regime switching behavior in the convenience yield.

Focusing on Chinese monetary policy, Klingelhöfer and Sun (2018) estimated a forward-looking Taylor-type monetary policy reaction function. Employing a multiple-regime threshold regression model, they found evidence that the Chinese monetary policy reaction function was asymmetric after around 2000 and switched across three different regimes. Further, using a regime-switching approach, Lange (2018) developed a model to evaluate asymmetries in the responses of the Canadian economy to US business cycles. This study also advocated the model extension in this paper by taking into regime-switching framework was empirically effective.

It is noted that equity portfolio return analysis for Japan by employing regime switching approach was little seen in existing literature although Tsuji (2012, 2018a, 2018b) attempted such analyses. Thus, using regime-switching models, we analyze the portfolio returns and the corporate investment factor return in Japan in the following sections.

\section{Data}

This section describes the data for our empirical study. All monthly data were provided by Kenneth French and this paper uses percentage excess returns over risk-free rate of four bivariate-sorted Japanese equity portfolios. First are the excess returns of the portfolios, which are sorted by size and B/M ratios (hereinafter referred to as 'Size-B/M portfolios'). Second are the excess returns of the portfolios, which are sorted by size and operating profitability (hereinafter referred to as 'Size-OP portfolios').

Third are the excess returns of the portfolios, which are sorted by size and corporate investment (hereinafter referred to as 'Size-Inv portfolios'), and fourth are those of the portfolios, which are sorted by size and prior returns from 12-month prior to 2-month prior (hereinafter referred to as 'Size-Mom portfolios'). We also use the CMA factor return for Japan. Fama and French (2015) documented the details of these four portfolio and factor constructions. In this paper, the sample period spans from November 1990 to December 2017 and all returns are in US dollars. This study also uses the excess returns of Japanese overall stock market.

Table 1. Summary statistics of excess returns in Japan

\begin{tabular}{llllll}
\hline & Overall market & Size1-B/M5 & Size1-OP5 & Size1-Inv3 & Size1-Mom4 \\
\hline Mean & 0.1121 & 0.5480 & 0.6608 & 0.5577 & 0.5693 \\
Median & 0.3700 & 0.5700 & 0.7250 & 0.8200 & 0.4900 \\
Max. & 16.8800 & 24.4100 & 27.7900 & 25.5000 & 26.3500 \\
Min. & -16.2200 & -20.7400 & -18.9900 & -16.0900 & -18.9500 \\
SD & 5.5289 & 6.6564 & 7.4657 & 6.5997 & 6.0530 \\
Skewness & 0.2135 & 0.4131 & 0.5044 & 0.5209 & 0.4717 \\
Kurtosis & 3.5124 & 4.0924 & 3.9339 & 4.3034 & 4.2957 \\
\hline
\end{tabular}

Notes: In this table, SD means the standard deviation value, Max. denotes the maximum value, and Min. denotes the minimum value. The sample period spans November 1990 to December 2017 and the number of the observations is 326. 
We first pick up the highest return portfolios from the four kinds of bivariate-sorted Japanese equity portfolios. All four Japanese portfolios include 25 portfolio returns since all have $5 \times 5=25$ portfolios as a result of bivariate sorting by Kenneth French. Checking the average excess return values of the above-mentioned four Japanese equity portfolios, in 25 Size-B/M portfolios, the smallest and the highest B/M portfolio records the highest return (hereinafter referred to this portfolio as 'Size1-B/M5'), and in 25 Size-OP portfolios, the smallest and the highest operating profitability portfolio shows the highest return (hereinafter referred to this portfolio as 'Size1-OP5'). Similarly, in 25 Size-Inv portfolios, the smallest and moderate investment portfolio exhibits the highest return (hereinafter referred to this as 'Size1-Inv3'), and in 25 Size-Mom portfolios, the smallest and the second highest prior return portfolio records the highest return (hereinafter 'Size1-Mom4').

Based on the evidence, we display the descriptive statistics as to the excess returns over risk-free rate regarding the four Japanese higher return equity portfolios in Table 1. From the mean excess return values in Table 1, we understand that in Japan, Size1-OP5 exhibits the highest return of 0.66 percent per month and Size1-Mom4 shows the second highest return of 0.57 percent per month.

As Table 1 displays, as the average excess return of the Japanese overall equity market is 0.11 percent per month, not only Size1-OP5 and Size1-Mom4, but also Size1-B/M5 and Size1-Inv3 exhibit higher returns than overall stock market in Japan (The average excess returns of Size1-B/M5 and Size1-Inv3 are 0.55 and 0.56 percent per month, respectively). Table 1 also shows that all the four Japanese excess portfolio returns are positively skewed and have fat-tailed distributions since all the returns present positive skewness values and higher kurtosis values than three, which is the kurtosis value of normal distributions. As above, we understand that in Japan, operating profitability is more effective factor than other factors to construct profitable portfolios, and unlike US or Europe, momentum effects are weaker in Japan.

Table 2. Results of Markov switching regressions with two CMA loading regimes

\begin{tabular}{|c|c|c|c|c|c|}
\hline \multicolumn{3}{|c|}{ Panel A. Size1-B/M5 Portfolio } & \multicolumn{3}{|c|}{ Panel B. Size1-OP5 Portfolio } \\
\hline \multicolumn{3}{|c|}{ High CMA loading regime } & \multicolumn{3}{|c|}{ High CMA loading regime } \\
\hline & Estimates & $p$-value & & Estimates & $p$-value \\
\hline Constant & -1.0355 & 0.2102 & Constant & -0.5021 & 0.5406 \\
\hline CMA & $2.2362 * * *$ & 0.0000 & CMA & $1.1340 * * *$ & 0.0000 \\
\hline \multicolumn{3}{|c|}{ Low CMA loading regime } & \multicolumn{3}{|c|}{ Low CMA loading regime } \\
\hline & Estimates & $p$-value & & Estimates & $p$-value \\
\hline Constant & $1.0829 * * *$ & 0.0093 & Constant & $1.8219 * * *$ & 0.0060 \\
\hline CMA & -0.0609 & 0.7198 & CMA & $-1.5207 * * *$ & 0.0000 \\
\hline $\ln \sigma$ & $1.7933 * * *$ & 0.0000 & $\ln \sigma$ & $1.9027 * * *$ & 0.0000 \\
\hline LL & \multicolumn{2}{|c|}{-1056.1750} & LL & \multicolumn{2}{|c|}{-1097.311} \\
\hline \multicolumn{3}{|c|}{ Panel C. Size1-Inv3 Portfolio } & \multicolumn{3}{|c|}{ Panel D. Size1-Mom4 Portfolio } \\
\hline \multicolumn{3}{|c|}{ High CMA loading regime } & \multicolumn{3}{|c|}{ High CMA loading regime } \\
\hline & Estimates & $p$-value & & Estimates & $p$-value \\
\hline Constant & -0.9481 & 0.2683 & Constant & $-1.1234^{*}$ & 0.0717 \\
\hline CMA & $1.9968 * * *$ & 0.0000 & CMA & $1.0706^{* * *}$ & 0.0000 \\
\hline \multicolumn{3}{|c|}{ Low CMA loading regime } & \multicolumn{3}{|c|}{ Low CMA loading regime } \\
\hline & Estimates & $p$-value & & Estimates & $p$-value \\
\hline Constant & $1.0437 * * *$ & 0.0100 & Constant & $1.7036^{* * *}$ & 0.0001 \\
\hline CMA & -0.1781 & 0.2937 & CMA & $-0.5185^{* *}$ & 0.0192 \\
\hline $\ln \sigma$ & $1.8049 * * *$ & 0.0000 & $\ln \sigma$ & $1.7066^{* * *}$ & 0.0000 \\
\hline LL & & & LL & -1 & \\
\hline
\end{tabular}

Notes: This table shows the estimation results of our two-regime Markov switching models. The sample period is from November 1990 to December 2017. LL means the log-likelihood value. ***,**, and * indicate the statistical significance of the estimates at the $1 \%, 5 \%$, and $10 \%$ levels, respectively. CMA means the conservative investment factor return premium of Fama and French (2015). 


\section{The Model}

This section documents the specification of the model for our empirical examinations. For our study, we employ the following Markov switching model (1). To investigate the profitability and the linkages between Japanese equity portfolio returns and the corporate investment factor return, CMA, we specify this model to have high and low CMA factor loading regimes as follows:

$$
r_{t}=\alpha_{m}+c_{m} C M A_{t}+\sigma \tau_{t} .
$$

In equation (1), $r_{t}$ denotes the excess return of one of the four Japanese equity portfolios, that is, Size1-B/M5, Size1-OP5, Size1-Inv3, or Size1-Mom4. Further, $\alpha_{m}$ indicates the constant term of the model, and this term depends on regime, $m$. In addition, in model (1), $C M A_{t}$ means the CMA factor return, and $c_{m}$ denotes its regime-dependent coefficient. Further, the disturbance term, $\tau_{t}$, is assumed to follow a standard normal distribution, and this disturbance term is also assumed to be independent and identically distributed (iid). As explained, our model (1) has two regimes, namely, high and low CMA factor loading regimes of common volatility, $\sigma$; and in this study, all model parameters are estimated by the maximum likelihood method.

\section{Empirical Results and Interpretations}

\subsection{Estimation Results of Markov Switching Models and CMA Loading Regime Probabilities}

This section explains our empirical results. Table 2 exhibits the estimation results of our Markov switching models with high and low CMA factor loading regimes. In addition, Figure 1 displays the Markov switching high and low CMA factor loading regime probabilities for the four Japanese equity portfolios analyzed in this study. These regime probabilities are also derived from our model (1).

First, from Panel A of Table 2, as the values of estimates for the coefficients of CMA suggest, for Size1-B/M5 portfolio, there are clearly two regimes: one is positively related to CMA and the other is little related to CMA. From Panel A of Figure 1, we understand that before around 1999, Size1-B/M5 portfolio return was positively related to CMA, while after that, this portfolio return has been little related to CMA.

Next, from Panel B of Table 2, as the values of estimates for the coefficients of CMA indicate, for Size1-OP5 portfolio, there are clearly two regimes, that is, one is positively related to CMA and the other is negatively related to CMA. From Panel B of Figure 1, it is understood that before around 2004, Size1-OP5 portfolio return was positively related to CMA, while after that, this portfolio return has been negatively related to CMA in general.

Further, as Panel C of Table 2, as the values of estimates for the coefficients of CMA suggest, for Size1-Inv3 portfolio, again, there exist clearly two regimes. Namely, similar with Size1-BM5 portfolio return, one is positively related to CMA and the other is little related to CMA. From Panel C of Figure 1, similar with Size1-B/M5 portfolio return, before around 1999, Size1-Inv3 portfolio return was positively related to CMA, while after that, this portfolio return has been little related to CMA.

Moreover, from Panel D of Table 2, as the values of estimates for the coefficients of CMA indicate, for Size1-Mom4 portfolio, there are again clearly two return regimes. That is, similar with Size1-OP5 portfolio return, one is positively related to CMA and the other is negatively related to CMA. From Panel D of Figure 1, we understand that before around 2004, Size1-Mom4 portfolio return was positively related to CMA, while after that, this portfolio return has been negatively related to CMA.

\subsection{Accumulated Returns of CMA and Equity Portfolios}

Finally, to further consider the linkages between the CMA factor return and the four Japanese equity portfolio excess returns analyzed in this paper, we display the accumulated returns of CMA and accumulated excess returns of the four Japanese equity portfolios in Figure 2. As this figure shows, recently, the linkages between CMA and the four Japanese equity portfolios become weaker, and the four Japanese equity portfolio returns perform more strongly than CMA factor returns. This evidence is consistent with the statistically significantly positive constant terms in low CMA factor loading regimes shown in Panels A to D of Table 2. That is, in recent periods, all the four Japanese portfolios yield higher returns than CMA with showing weaker linkages between the CMA factor return. This is the recent situation of the performances regarding the four Japanese higher return equity portfolios examined in this paper.

As above, it is emphasized that our empirical results obtained from the two-regime Markov switching models are rather clear and consistent with all the four Japanese equity portfolios. Our results also demonstrate that the use of the regime-switching models carefully designed like ours is quite useful for deriving the new interesting evidence for the fields of business, economics, and finance. 
Panel A. Size1-B/M5 Portfolio

High CMA loading regime

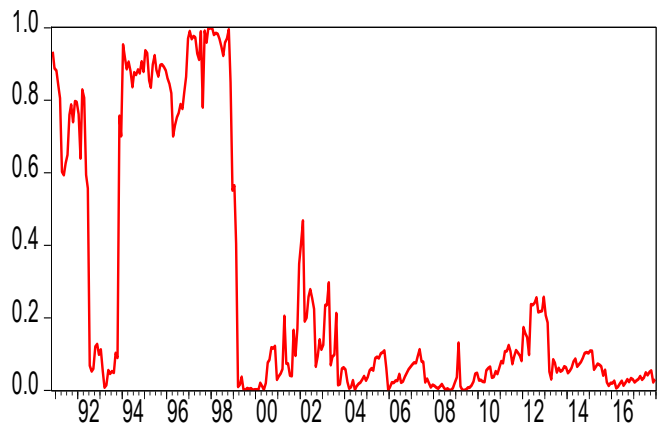

Low CMA loading regime

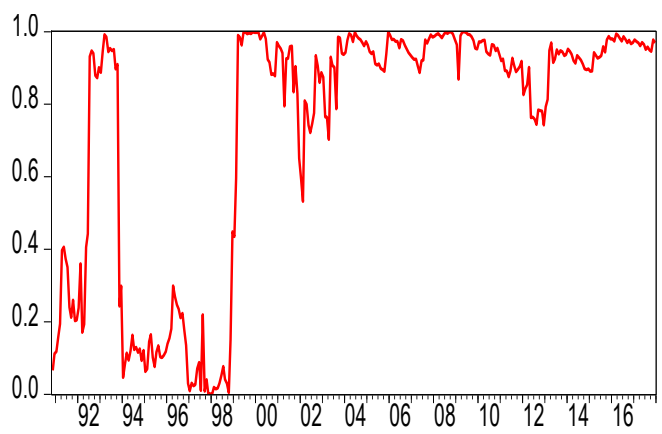

Panel C. Size1-Inv3 Portfolio

High CMA loading regime

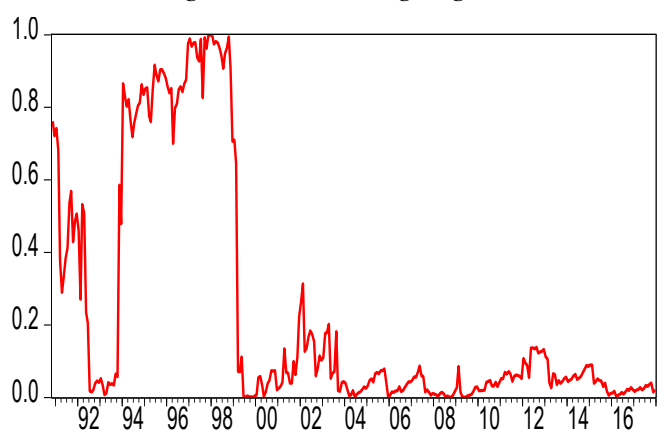

Low CMA loading regime

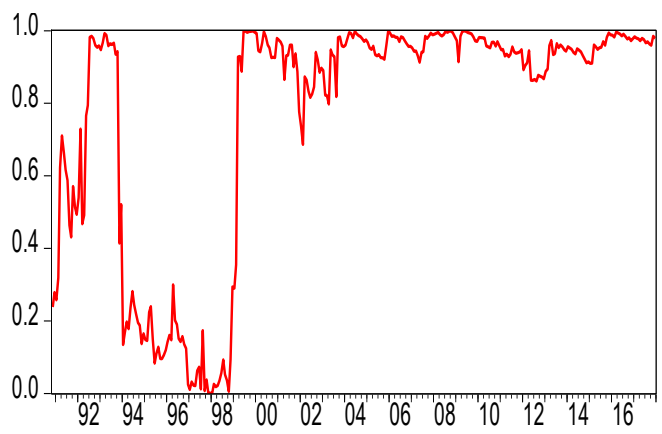

Panel B. Size1-OP5 Portfolio

High CMA loading regime

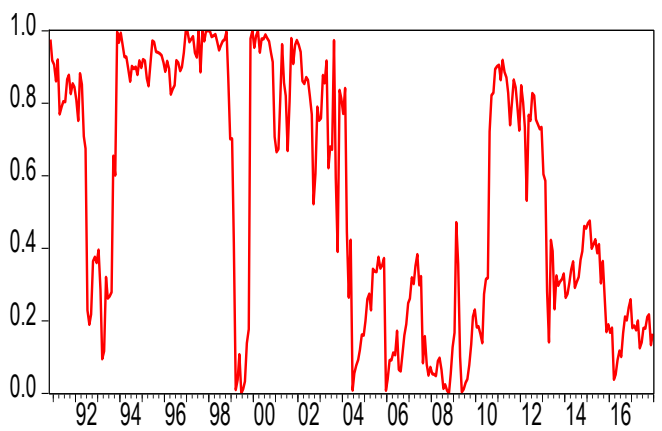

Low CMA loading regime

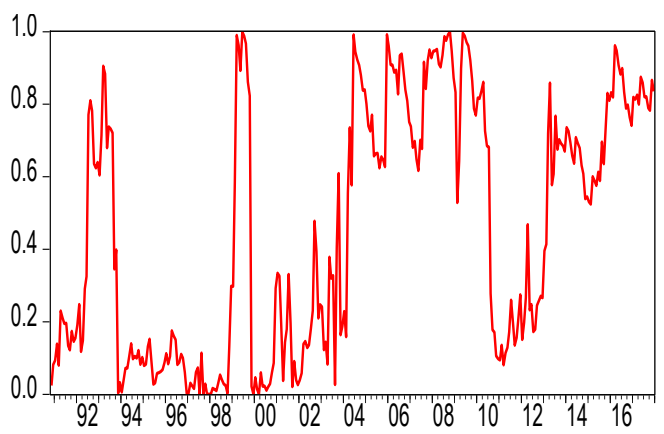

Panel D. Size1-Mom4 Portfolio

High CMA loading regime

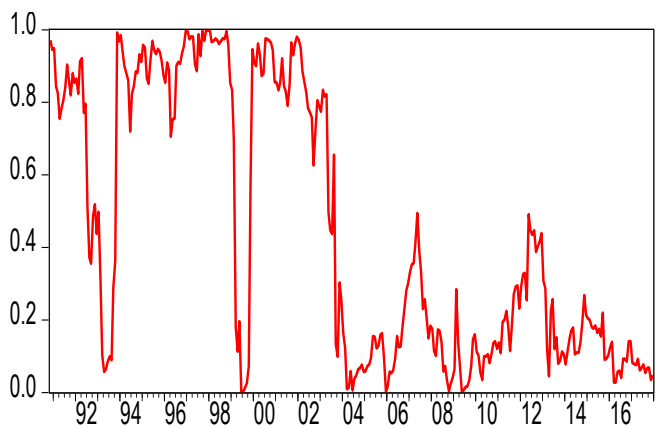

Low CMA loading regime

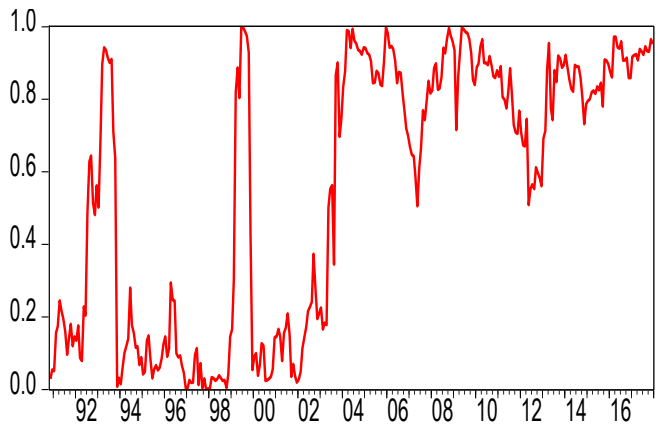

Figure 1. Markov switching regime probabilities: High and low CMA loading regimes 


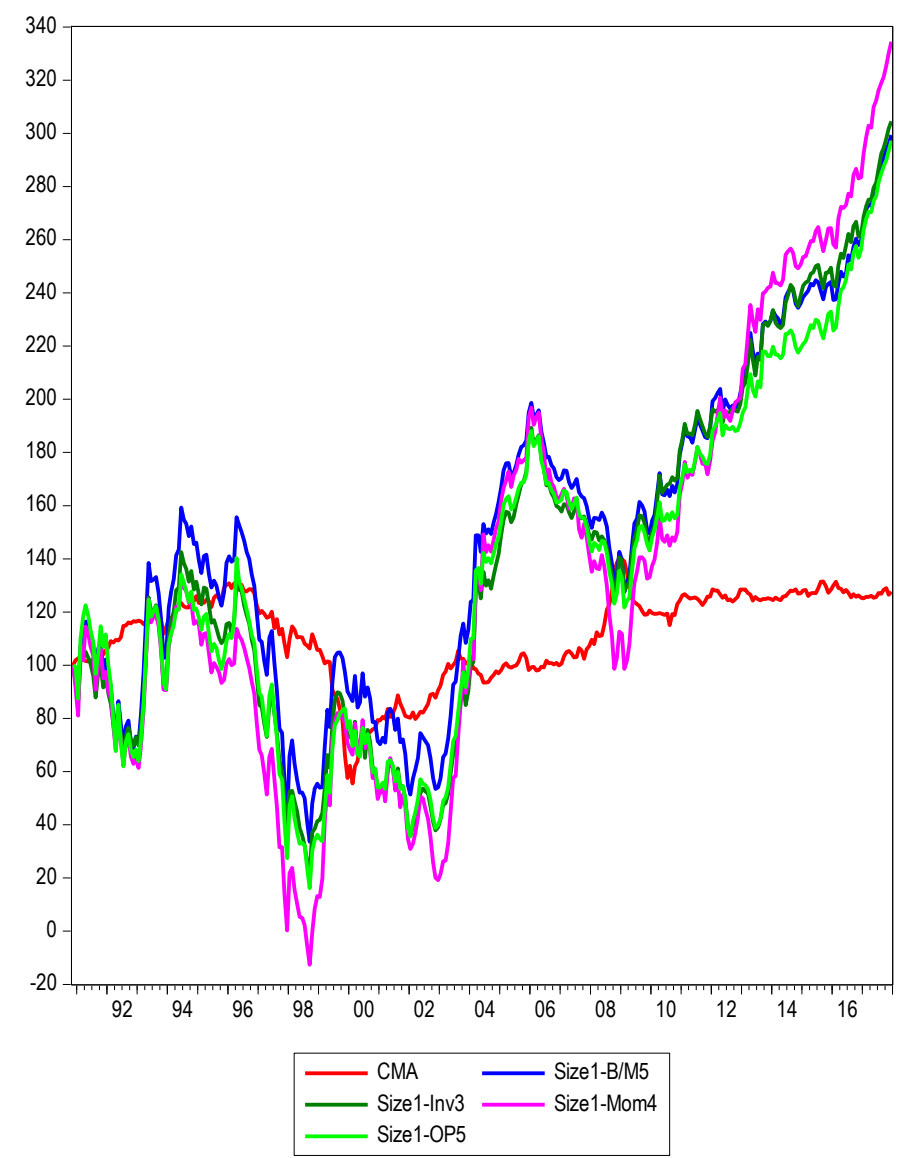

Figure 2. Accumulated returns of CMA and four higher return portfolios in Japan

\section{Conclusions}

This paper explored the profitability of the four Japanese higher return equity portfolios and their linkages between conservative investment factor return premiums suggested by Fama and French (2015). For the period from November 1990 to December 2017, the smallest and the highest B/M portfolio, the smallest and the highest operating profitability portfolio, the smallest and moderate investment portfolio, and the smallest and the second highest prior return (momentum) portfolio recorded higher returns in Japan. Using the Markov switching models with high and low investment factor loading regimes, we obtained the following interesting evidence.

(1) First, in the four Japanese higher return equity portfolios, the smallest and the highest operating profitability portfolio presented the highest return. While excess overall equity market return in Japan was 0.11 percent per month, the smallest and the highest operating profitability portfolio exhibited the average excess return of 0.66 percent per month in Japan.

(2) Second, the smallest and the highest B/M portfolio, the smallest and moderate investment portfolio, and the smallest and the second strongest momentum portfolio also recorded higher excess returns than the overall equity market in Japan. These mean the effectiveness of building bivariate-sorted equity portfolios in Japan.

(3) Moreover, our analyses via two-regime Markov switching models evidenced that for all the four Japanese equity portfolios, there were clearly two regimes: one was positively related to the investment factor return and the other was little or negatively related to the investment factor return. In addition, our analyses revealed that recently, all the four Japanese portfolios yielded higher returns than the investment factor return with exhibiting weaker linkages between the investment factor return.

As demonstrated in this study, when the data and the model are well fitted, applying regime switching models to examine financial and economic data is effective and useful for deriving new findings for the fields of business, 
economics, and finance. Extended research by employing similar approach by using different data sets should be meaningful, and thus it is one of our future works.

\section{Acknowledgements}

The author firstly appreciates this journal for its repeated kind article invitation. The author also highly appreciates Jenny Zhang for her kind editorial assistance to this paper. Moreover, the author thanks an editor of this journal and an anonymous referee for their constructive and supportive comments on this paper. In addition, the author also greatly appreciates the Japan Society for the Promotion of Science Grant-in-Aid for Scientific Research and the Chuo University Personal Research Grant for their generous financial assistance to my research. Finally, I deeply thank all the Editors of this journal for their kind attention to my paper.

\section{References}

Almansour, A. (2016). Convenience yield in commodity price modeling: A regime switching approach. Energy Economics, 53, 238-247. http://dx.doi.org/10.1016/j.eneco.2014.06.016

Baele, L., Bekaert, G., Cho, S., Inghelbrecht, K., \& Moreno, A. (2015). Macroeconomic regimes. Journal of Monetary Economics, 70, 51-71. http://dx.doi.org/10.1016/j.jmoneco.2014.09.003

Chun, O. M., Dionne, G., \& François, P. (2014). Credit spread changes within switching regimes. Journal of Banking \& Finance, 49, 41-55. http://dx.doi.org/10.1016/j.jbankfin.2014.08.009

Fama, E. F., \& French, K. R. (1993). Common risk factors in the returns on stocks and bonds. Journal of Financial Economics, 33, 3-56. https://doi.org/10.1016/0304-405X(93)90023-5

Fama, E. F., \& French, K. R. (2015). A five-factor asset pricing model. Journal of Financial Economics, 116, 1-22. https://doi.org/10.1016/j.jfineco.2014.10.010

Filardo, A. J. (1994). Business-cycle phases and their transitional dynamics. Journal of Business \& Economic Statistics, 12, 299-308. http://dx.doi.org/10.1080/07350015.1994.10524545

Filipova, K., Audrino, F., \& De Giorgi, E. (2014). Monetary policy regimes: Implications for the yield curve and bond pricing. Journal of Financial Economics, 113, 427-454. http://dx.doi.org/10.1016/j.jfineco.2014.05.006

Gibson, R., \& Schwartz, E. S. (1990). Stochastic convenience yield and the pricing of oil contingent claims. Journal of Finance, 45, 959-976. http://dx.doi.org/10.1111/j.1540-6261.1990.tb05114.x

Hamilton, J. D. (1989). A new approach to the economic analysis of nonstationary time series and the business cycle. Econometrica, 57, 357-384. http://dx.doi.org/10.2307/1912559

Klingelhöfer, J., \& Sun, R. (2018). China's regime-switching monetary policy. Economic Modelling, 68, 32-40. http://dx.doi.org/10.1016/j.econmod.2017.04.017

Lange, R. H. (2018). The effects of the U.S. business cycle on the Canadian economy: A regime-switching VAR approach. The Journal of Economic Asymmetries, forthcoming. https://doi.org/10.1016/j.jeca.2017.12.001

Tsuji, C. (2012). Positive return premia in Japan. Quantitative Finance, 12, $345-367$. http://dx.doi.org/10.1080/14697688.2010.541485

Tsuji, C. (2018a). Value premium and portfolio return regime: Evidence from European equities. Modern Economy, forthcoming.

Tsuji, C. (2018b). Volatility regime and equity portfolio return: Evidence from Europe. Applied Economics and Finance, forthcoming. 